\title{
Berichte.
}

\section{Hauptversammlung des Historischen Vereins für den Niederrhein zu Münstereifel am 20. Oktober 1913.}

An einem verhältnismüssig späten, aber schönen Herbsttage versammelten sich Montag, den 20. Oktober 1913, die Mitglieder und Freunde des Historischen Vereins fur den Niederrhein in dem malerischen Städtchen Münstereifel, um auf der fällig gewordenen Herbstversammlung die geschäftlichen Angelegenheiten des Vereins zu erledigen und durch die Teilnahme an den Vorträgen und Besichtigungen ibre Kenntnisse in der Landesgeschichte zu vervollkommnen. Bei einer grossen Anzahl der Teilnehmer mag auch die Absicht mitgewirkt haben, in Münstereifel mit dem einen oder anderen Freund zusammenzutreffen und das Band der persönlichen Beziehungen unter den Vereinsgenossen enger zu knüpfen. Denn auch für diesen Zweck sind unsere zweimal im Jabre stattfindenden Wanderversammlungen vorzüglich geeignet. Dank der umsichtigen Arbeit des vorbereitenden Ortskomitees, dem vor allem die Herren Bürgermeister Schumacher, Oberpfarrer Hochscheid und Gymnasialdirektor Dr. M eye $r$ aus Münstereifel angebörten, war für die Versammlung eine sehr reichhaltige Tagesordnung aufgestellt, die gewiss nicht wenig zu dem zahlreichen Besuch der auswärtigen Mitglieder beigetragen hat. Mit feinem Verständnis batte man als Versammlungslokal den grossen Saal der neuhergestellten Burg bestimmt, von dessen Umgebung aus sich den Teilnebmern eine herrliche Aussicht auf die Stadt Münstereifel und das sie umgebende Landschaftsbild darbot.

Nachdem die Teilnehmer den Burghügel hinaufgewandert waren, wurde die Versammlung um 10 Ohr von dem Vorstandsmitgliede Herrn Gymnasialdirektor Dr. Brüll aus Mülheim am Rhein eröffnet. Er hielt eine kurze, herzliche Begrüssungsansprache 
ill die Erschienenen und gedachte u. a. auch des am 13. Juni 1913 zı Elberfeld gefeierten fünfrigjährigen Jubelfestes des Bergischen Geschichtsvereins, an dem er als Vertreter des Historischen Vercins für den Niederrhein teilgenommen batte. Herr Bürgermeister Schumacher aus Münstereifel entbot als Oberbaupt des 'Tagungsortes besonders den auswärtigen Teilnehmern seinen herzlichsten Willkommensgruss, der von der Versammlung dankbar aufgenommen wurde.

In der Todeschronik sind die Herren Universitätsprofessor Dr. Jakob Kirsebkamp in Bonn (Mitglied seit 1904), Pfarrer ockenfels in Oberwinter (1906), Leopold Romen in Kleve (1906), Kaplan Hubert Schmitz in Freiburg i. B. (1904) und Landgerichtsrat $J$ osef Seuwen in Köln (1906) zu erwähnen. Ausserdem starb noch am Vorabende des Versammlungstages der lfarrer von St. Kunibert in Köln Anton Ditges, der bereits seit 1879 dem Verein angehörte und durch seinen freundlichen ('harakter und seine wissenschaftlichen Interessen, besonders auf dem Gebiete der kirchlichen Kunst, sicb zallreiche Freunde innerlıalb unseres Verbandes erworben hatte. Der Historische Verein für den Niederrhein wird allen seinen hingeschiedenen Mitgliedern, die ibm bis zum Tode tren geblieben sind, ein dankbares Andenken bewahren.

Als weiteren Gegenstand der Tagesordnung teilte der Schatzmeister Schilling die Bilanz der Jabresrechnung mit, die in diesem Hefte veröffentlicht ist. Das Amt der Rechnungsprïfer ïbernahmen wiederum in dankenswerter Weise die Herren Landgerichtsrat $\mathrm{Dr}$. $\mathrm{R}$ isbroeck und Assessor Sch ïller aus Köln.

Für die nächste Frübjahrsversammlung wurde von Herrn (oberlehrer Dr. van Laak Linz vorgeschlagen, wo der Verein zum letzten Male im Jahre 1886 getagt hatte. Die Versammlung erklärte sich mit diesem Vorschlage einverstanden.

Infolge eines Wechsels in der Leitung der Redaktionsreschäfte, die aus den Händen des Herrn Vorsitzenden Professors Dr. Schrörs in die des Vorstandsmitgliedes Herrn Privatdozenten Dr. Neuss übergegangen ist, hatte sich leider das Erscheinen des zu Herbst fälligen Annalenheftes verzögert. Inzwischen ist jedoch das 95. Heft der Annalen zu Beginn des neuen Jahres erschienen und die pünktliche Ausgabe des folgenden Heftes sichergestellt. 
Den wissenschaftlichen T'eil der Hauptversammlung eröffnete Herr Gymnasialdirektor Dr. Peter Meyer aus Münstereifel mit einem Vortrage "Über die Geschichte des Versammlungsortes und seiner Umgebung bis zur Gründung des Novum Monasterium Eifliae unter Berïckssichtigung des vor kurzem ausgegrabenen Matronen. heiligtums im benachbarten Pesch ". Der Herr Vortragende behandelte in der Einleitung die geologische Entstehungsgeschichte der Erdoberfläche der jetzigen Münstereifler Gegend, erwähnte sodann die dort noch vorbandenen Kulturüberreste aus der prähistorischen und urgermanischen Zeit (Cacushöhle, altgermanischer Ringwall auf der Haar) und verbreitete sich ausführlicher uber die römische Periode (römische Münzen, Statio belgica, Römerkanal, Matronen. heiligtum in Pesch). Er schloss mit einer kurzen Úbersicht über die fränkischen Funde und die Anlage des Benediktinerklosters Novum Monasterium Eifliae, das ca. 830 durch Abt Marquard vou Prüm gegründet wurde und der späteren Stadt Münstereifel den Namen gegeben hat. Nicht nur dureb den interessanten Inhalt, sondern auch durch die frische, bisweilen etwas humoristisch gefärbte Form der Darstellung wusste der Herr Vortragende die Aufmerksamkeit der Hörer von Anfang bis zu Ende zu fesseln. Besonders beifällig wurden die Stellen aufgenommen, an deneu der Redner, der selbst eifrig auf dem Gebiete der heimischen Archäologie gearbeitet hat, die Verdienste der anwesenden Altertumsfreunde, namentlich der Herren Pfarrer $\mathrm{Kr}$ a use in Esch. weiler und Professor Hürten in Münstereifel würdigte. Dadurch, dass der Herr Redner eine Disposition seines Vortrages verteilte und seine Ausführungen an einer eigens gezeichneten Karte erläuterte, wurde das Verständnis der gehaltreichen und vielseitigen Darlegungen wesentlich erleichtert.

Der Versammlungsleiter Herr Direktor Brüll sprach dem Herrn Vortragenden für seine interessanten und lebrreichen Ausführungen den offiziellen Dank des Vereins aus, nachdem bereits die Versammlung durch spontanes Beifallklatschen ihrem Danke und ihrer Anerkennung Ausdruck gegeben hatte. Hierauf wurde die Versammlung durch eine balbstündige Frühstückspause unterbrochen, während deren in der Burgwirtschaft Speisen und Erfrischungen dargeboten wurden.

Den zweiten Vortrag hielt der Assistent des Eirbischöfliche川 Konvikts Josephinum in Münstereifel, Herr Adolf Kalsbach. 
Wr hatte das Thema "Die Jesuiten in Münstereifel von 1625 bis $16+9^{4}$ gewählt und verbreitete sich hauptsächlich über die Gründungsgeschichte der Niederlassung des Jesuitenordens in Münstereifel, die besonders durch den Pfalzgrafen Wolfgang Wilhelm bemiinstigrt wurde, die grossartige Wirksamkeit der Jesuiten auf der sogenannten Eifelmission, und die 1629 von den Jesuiten gestiftete Marianische Sodalität, durch die der Orden namentlich unter ler Biirgerschaft Münstereifels festen Fuss fasste. Als erster Jesuit fand P. Heinrich Rinkop mit einem Laienbruder in der Woluung des Stiftsherrn Hermann Gebour 1625 eine gastliche Anfualume. Im Jahre 1649 wurde die bisherige Residenz in ein Kolleg umgewandelt, und damit trat die Niederlassung in ein neues Strdium ibrer Entwicklung.

Dieser formell wie inhaltlich sorgfältig ausgearbeitete Tortrag ïher eine wichtige Periode der neueren Kirchengeschichte Münstereifels wurde mit grossem Interesse angehört. Am Schlusse wurde der Herr Vortragende von der Versammlung und dem Versammlıuıssleiter mit der grössten Anerkennung belohnt.

Nachdem Herr Direktor Dr. Brïll die Versammlung geschlossen latte, begaben sich die Teilnehmer in die Stiftskirche, deren Geschichte und Kunstschätze Herr Oberpfarrer Hochscheid in ebenso liebenswürdiger wie sachverständiger Weise erläuterte. Besondere Aufmerksamkeit erregten die Säulen aus dem Kalksinter des ehemaligen Römerkanals und der herrliche Sarkophag des Ritters Gottfried von Bergheim $\dagger$ 1335. Auch die kustbaren Paramente und der neue Hochaltar fanden grosses Interesse. Den Besuch des Deutschen Kaisers im Jahre 1912 hat cine Inschrift verewigt. Es ist mir eine angenehme Pflicht, Herrn Oberpfarrer Hochscheid, dem sachverständigen Hüter der kirchlichen Kunstschätze Münstereifels, für seine grossen Bemühungen den wärmsten Dank des Vereins abzustatten. Er hatte es sich nicht nehmen lassen, ausserdem noch im Pfarrhause eine kleine Ausstellang von alten Kupferstichen und den ältesten Beständen des Pfarrarchivs zu veranstalten, die mit grossem Interesse besichtigt wurde.

Das iibliche gemeinschaftliche Mittagessen fand um $1^{1} / 2$ Uhr im Hotel Hillebrandt statt. Während des Mahles erfreute die Schiilerkapelle des Gymnasiums die Tisehgenossen durch vorzïglichı musikalische Darbietungen, wofür ibr Herr Gymnasial- 
direktor Dr. Weisweiler in Dïren (früher in Münstereifel) mit lannigen Worten den Dank abstattete. Herr Gutsbesitzer S tomps war in seiner kräftigen Propagandarede wiederum eifrig für die Gewinnung neuer Mitglieder bemüht, wofür ihm auch an dieser Stelle herzlich gedankt sei. Herr Direktor Dr. B rüll toastete auf Münstereifel, Herr Bürgermeister Sçhumacher anf den Histo. rischen Verein und Herr Oberpfarrer Hochscheid auf den Versammlungsleiter.

Am Schlusse der Tagnng teilten sicb die Besucher in mehrere Gruppen: eine Gruppe besichtigte anter der Führung des Herrn Professors Hürten die Sehenswürdigkeiten der Stadt und ihrer Umgebung, eine zweite machte eine Wagenfahrt nach dem Matronenheiligtum in Pesch, während andere Gruppen sich zn selbstgewählten Spaziergängen zusammenschlossen. Der im offiziellen Programm in Aussicht genommene Besuch des Römerkanals in Weingarten kam nicht zur Ausfübrung.

Bonn.

N. Hilling. 